\title{
Studies on the changes in phenological, growth and physiological responses of Silene capitata Kom., an endangered plant in Korea, under climate change treatment
}

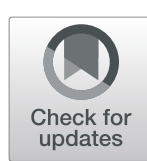

Jae-Hoon Park ${ }^{1,2}$, Young-Sub Han ${ }^{1,3}$, Eung-Pil Lee', Seung-Yeon Lee ${ }^{1}$, Heon-Mo Jeong ${ }^{4}$ and Young-Han You ${ }^{1 *}$ (D)

\begin{abstract}
Background: This research aims to study the effect of climate change on the phenology, growth, and physiological traits of Silene capitata Kom., a Korean endangered species II. This study increased $\mathrm{CO}_{2}$ concentration in a closed glass greenhouse, with the daily mean temperature and $\mathrm{CO}_{2}$ concentration respectively being $4.61^{\circ} \mathrm{C}$ and $93.63 \mathrm{ppm}$ higher than the outside temperature (ambient conditions, control). The seeds of $\mathrm{S}$. capitata were sown in control and treatment environments in March 2013 while seedlings were transplanted into individual pots in May 2013. To research phenological changes, the first day of the flowering and ripening of the plants transplanted in 2013 and first day of leafing in 2014 were observed. The growth and physiological responses of mature leaves were also studied in 2013.
\end{abstract}

Results: There was no difference in the first day of flowering, but the first day of ripening was earlier in the treatment group than the control group. There was no difference in the number of rosette leaves between the two groups, but leaf area was wider in the treatment group than the control group. Transpiration rate and stomatal conductance were higher in the treatment group than the control group, chlorophyll content decreased, and photosynthetic rate and water use efficiency were the same for both groups. As a result of simple regression analysis among the transpiration rate, stomatal conductance, photosynthetic rate, and water use efficiency, stomatal conductance increased when transpiration rate increased. Stomatal conductance increased with photosynthetic rate in the control unlike in the treatment group. The photosynthetic rate and water use efficiency increased with transpiration rate in the control group unlike in the treatment group. Furthermore, water use efficiency increased as photosynthetic rate increased in both groups.

Conclusion: Due to high $\mathrm{CO}_{2}$ concentration, the photosynthetic rate was no longer controlled by the stomata, which appeared to suppress the excessive production of photosynthetic products by reducing chlorophyll content. It is believed that the phenological responses of S. capitata under climate change conditions will advance and that stable growth will be difficult in regions lacking moisture due to the high transpiration rate.

Keywords: Caryophyllaceae, $\mathrm{CO}_{2}$ concentration, Ecophysiology, Global warming, Perennial herb

\footnotetext{
* Correspondence: youeco21@kongju.ac.kr

'Department of Biological Science, Kongju National University, Gongju-si,

Chungcheongnam-do 32588, Republic of Korea

Full list of author information is available at the end of the article
}

(c) The Author(s). 2019 Open Access This article is distributed under the terms of the Creative Commons Attribution 4.0 International License (http://creativecommons.org/licenses/by/4.0/), which permits unrestricted use, distribution, and reproduction in any medium, provided you give appropriate credit to the original author(s) and the source, provide a link to the Creative Commons license, and indicate if changes were made. The Creative Commons Public Domain Dedication waiver (http://creativecommons.org/publicdomain/zero/1.0/) applies to the data made available in this article, unless otherwise stated. 


\section{Background}

Due to the recent global climate change, land and ocean surface temperatures are reported to have increased by $0.85^{\circ} \mathrm{C}$ over the last 30 years (IPCC 2014). The annual average temperature change rate in Korea has increased from 0.23 to $0.5^{\circ} \mathrm{C}$ per decade from 1954 to 2010 (Ministry of Environment 2018). Assuming this trend continues, the temperature change rate between 2017 and 2100 is estimated to be $5.3^{\circ} \mathrm{C}$ per decade (Ministry of Environment 2018).

The main causes of accelerating climate change are the artificial production and accumulation in the atmosphere of greenhouse gases that absorb or reflect solar radiation back to the Earth's surface (IPCC 2014; National Institute of Meteorological Sciences 2017). $\mathrm{CO}_{2}$ is a type of greenhouse gas and a leading cause of climate change, caused by human fossil fuel consumption. The average global $\mathrm{CO}_{2}$ concentration in 2017 was reported at $405 \mathrm{ppm}$ (National Institute of Meteorological Sciences 2017). In Korea, the annual average $\mathrm{CO}_{2}$ concentration measured at $412.2 \mathrm{ppm}$ in Anmyon Island, which has the longest historical and real-time database of $\mathrm{CO}_{2}$ concentration in the country, has been observed to be steadily increasing since 1999 (National Institute of Meteorological Sciences 2017).

Climate change affects the geological range, migratory patterns, species disturbance, and interspecific interactions of many species in terrestrial, freshwater, and marine habitats on the planet. It also induces changes in the phenological responses of plants (Richardson et al. 2013). Recently, phenological changes due to climate change in temperate forests have shown a tendency for longer growing seasons due to earlier leafing in spring, later leaves falling in autumn (Richardson et al. 2013). In addition, accelerated plant phenology, due to raised annual temperature and precipitation caused by climate change, has been reported (Ministry of Environment 2018). Therefore, several studies on climate change and plant phenological responses have been published in Korea (Kim and You 2010b; Han et al. 2012; Lee et al. 2012; Shin and You 2012; Choi and Jung 2014; Park et al. 2014a; Park et al. 2014b).

Moreover, if annual temperature increases by more than $4{ }^{\circ} \mathrm{C}$, substantial species extinction is predicted (IPCC 2014). Particularly in Asia, the impact of biodiversity, disease, and floods caused by continued climate change was found to be greater than in other regions (Ministry of Environment 2018). In the Korean peninsula, it was predicted that if the temperature increases by $0.5^{\circ} \mathrm{C}$, the distribution area of temperate broad-leaved evergreen forests will extend $80 \mathrm{~km}$ northward while that of cold-adapted plants will decrease (Ministry of Environment 2018).

In particular, a rare and endemic species is more vulnerable to the climate change (ISIIK 2011). Currently, the Korean Ministry of Environment is investigating and announcing species facing extinction in Korea (Ministry of Environment 2018). A total of 60 species of endangered wildlife class I and 207 species of class II have been designated. Plants make up 11 species in class I and 77 species in class II, accounting for approximately $33 \%$ of all endangered species (Ministry of Environment 2018). For this reason, some studies on the population characteristics, restoration, and conservation of rare and endangered plants have been conducted in Korea (Oh et al. 2014; Pi et al. 2015; Pi et al. 2016; Jeong et al. 2016; Jung et al. 2016; Lee et al. 2017).

Silene capitata Kom., an experimental plant in this study, is a Korean endangered wildlife class II plant and a Korean endemic plant designated as a vulnerable species on the IUCN National Red List (National Institute of Biological Resources 2011). This plant is a perennial herbaceous plant in the Caryophyllaceae family with a hairy stem and a shoot that grows up to $40 \mathrm{~cm}$ (National Institute of Biological Resources 2011). Its leaves are long, ovate, or lanceolate with an entire margin, and its pink flowers bloom in October to November (National Institute of Biological Resources 2011). The flower consists of tubular calyx with five-parted ends, five petals with split ends, 10 stamens attached to the underside of the petals, and two to four styles, with the seeds being black and kidney-shaped and with bumps on the edges (Lee 1975).

S. capitata is a northern plant, first reported in the northern part of Gangwon province in 1902. It is known to inhabit Hongcheon area and the limestone zone of Pyeongchang and Yeongwol area of Gangwon province, Yeoncheon of Gyeonggi province, Cheorwon, Pocheon area, and the cliff around the Hantan River in Korea, as well as Northeast China (Lee 1975; National Institute of Biological Resources 2011; Nam et al. 2012). They live mainly in sunny rock crevices in mountainous areas and are threatened by indiscriminate harvesting by climbers (National Institute of Biological Resources 2011). Some studies on chloroplast genome sequence analysis (Kang et al. 2017) and artificial cultivation for the preservation of species in plant factories (Park et al. 2016; Park et al. 2018) have been reported, but there have been few basic ecophysiology studies carried out because of their very narrow distribution range in the world.

Although many studies on the other endangered plants have been reported, different responses could appear for each plant because of their individual characteristics. Thus, the conservation study for a certain endangered species must be conducted on the basis of that species data. Thus, in order to uncover its response to a changing climate environment, this study investigated changes in the first day of flowering, fruit ripening and leafing, the number of rosette leaves, leaf areas, transpiration rate, stomatal conductance, photosynthetic rate, water use efficiency, chlorophyll 
content, and $\mathrm{Fv} / \mathrm{Fm}$ of S. capitata, a native Korean and endangered northern plant, under current atmospheric and climate change conditions from March 2013 to May 2014. These results will be used as basic data for understanding and conserving S. capitata against climate change.

\section{Materials and methods}

\section{Sowing and cultivation}

Three fruit pods of $S$. capitata growing in the habitats of Daejeon suburbs were collected in October 2012. Seeds were refrigerated at $4{ }^{\circ} \mathrm{C}$ until sowing and were sown on seeding plates while some pieces of newspaper were placed on the bottom and then filled with bed soil on March 20, 2013 and March 28, 2014, respectively. The sown seeds in 2014 were the seeds of flowers in each environmental group in 2013. Since the $S$. capitata seeds are very small, seeds were not covered by soil after seeding and water was supplied by spraying into the air using an atomizer so that the seeds are not washed out of the seeding plates by water drops. The soil was always kept wet. After that, germinated seedlings were transplanted into individual pots and 3 pots were placed in the control and treatment environments, respectively.

For cultivation, natural incident lights on the ground and bed soil (Hanareum horticultural bed soil, Shinsung Mineral Co., Seongnam, Republic of Korea) were used. Moisture in the bed soil was supplied at intervals of 2 to 3 days. But the time kept moisture in the soil could be changed because of changing the daily and seasonal evapotranspiration. Thus, the soil was checked daily to ensure it is kept wet.

\section{Climate change treatment}

A typical environmental change involves an increasing $\mathrm{CO}_{2}$ level and atmospheric temperature over time. Therefore, the $\mathrm{CO}_{2}$ concentration in the greenhouse at Kongju National University was increased, acting as the treatment environment, while the external environment was set as the control from January 2013 to May 2014.

The internal $\mathrm{CO}_{2}$ level of the greenhouse was controlled by injecting $\mathrm{CO}_{2}$ using a gas regulator with a 0.2mm-diameter tube connected. The internal temperature of the greenhouse was raised by increasing the $\mathrm{CO}_{2}$ concentration. $\mathrm{CO}_{2}$ concentration, temperature, and relative humidity inside and outside the greenhouse were measured by an LCSEMS sensor (Parus Co., Shanghai, China) every $10 \mathrm{~min}$, with the records transferred to a computer. However, temperature data from the Korea Meteorological Administration (2015) were used for the control group due to an error with the measuring sensor of the control environment.

The daily mean, maximum, and minimum temperatures of control were $11.09 \pm 10.36^{\circ} \mathrm{C}, 29.63^{\circ} \mathrm{C}$, and $-12.10^{\circ} \mathrm{C}$ and that of treatment were $15.70 \pm 8.13^{\circ} \mathrm{C}, 32.06^{\circ} \mathrm{C}$, and $1.06^{\circ} \mathrm{C}$, respectively. The daily mean temperature in the treatment environment was $4.61{ }^{\circ} \mathrm{C}$ higher than that in the control environment (Fig. 1a). The daily mean, maximum, and minimum $\mathrm{CO}_{2}$ concentration of control were $379.26 \pm 36.80 \mathrm{ppm}, 513.38 \mathrm{ppm}$, and $281.20 \mathrm{ppm}$ and that of treatment were $472.90 \pm 52.52 \mathrm{ppm}, 633.48 \mathrm{ppm}$, and $353.81 \mathrm{ppm}$, respectively. The daily mean $\mathrm{CO}_{2}$ concentration of the treatment environment was $93.63 \mathrm{ppm}$ higher than that of the control environment (Fig. 1b).

Considering that the IPCC scenarios predict that $\mathrm{CO}_{2}$ concentrations will reach about $450 \mathrm{ppm}$ at RCP 2.6 and about $580-720 \mathrm{ppm}$ at RCP 4.5 in 2100 years (IPCC 2014), the $\mathrm{CO}_{2}$ concentration in the treatment was determined to be a suitable concentration for confirming the response of $S$. capitata to the $\mathrm{CO}_{2}$ concentration when continuous occurring of climate change.

Mean relative humidity was measured with LCSEMS sensor. In the control and treatment, each mean relative humidity was $65.09 \pm 18.09$ and $74.06 \pm 18.79$. The photosynthetic photon flux densities (PPFDs) were measured with LCi Ultra Compact Photosynthesis System (ADC, Hoddesdon, UK) when measuring photosynthesis. In the control and treatment, each PPFD was 187.44 \pm $11.32 \mu \mathrm{molm}^{-2} \mathrm{~s}^{-1}$ and $133.86 \pm 26.29 \mu \mathrm{molm}^{-2} \mathrm{~s}^{-1}$.

\section{Phenological responses}

To understand the phenological changes of $S$. capitata as a result of climate change, the first days of flowering and fruit ripening in 2013 and leafing in 2014 were observed. "Before foliation" means the time of seed state in the soil (Fig. 2b). The observed duration was for 61 and 46 Julian days in 2013 and 2014. The leafing, flowering, and fruit ripening were set as opening cotyledons, opening petals, and observing stamens, observing black seeds by eye when occurring more than half of individuals.

\section{Growth and physiological responses}

To observe the growth response of S. capitata, in November 2013, one leaf from each plant was selected from the control and treatment groups, and their lengths and widths were measured. The leaf area was estimated by calculating the area of the elliptical shape with the long and short lengths equal to the leaf length and width. The number of rosette leaves per plant was counted.

For physiological response measurements, one leaf was selected from the upper, middle, and lower mature leaves of each plant in the control and treatment environments in November 2013. The transpiration rate $\left(\mathrm{mmolm}^{-2} \mathrm{~s}^{-1}\right)$, stomatal conductance $\left(\mathrm{mmolH}_{2} \mathrm{Om}^{-2} \mathrm{~s}^{-1}\right)$, and photosynthetic rate $\left(\mu \mathrm{molCO}{ }_{2} \mathrm{~m}^{-2} \mathrm{~s}^{-1}\right)$ were measured using the LCi Ultra Compact Photosynthesis System.

The water use efficiency $\left(\mu \mathrm{molCO}_{2} \mathrm{mmolH}_{2} \mathrm{O}^{-1}\right)$ was calculated by dividing the photosynthetic rate by the transpiration rate. Chlorophyll content (CCI) was measured 

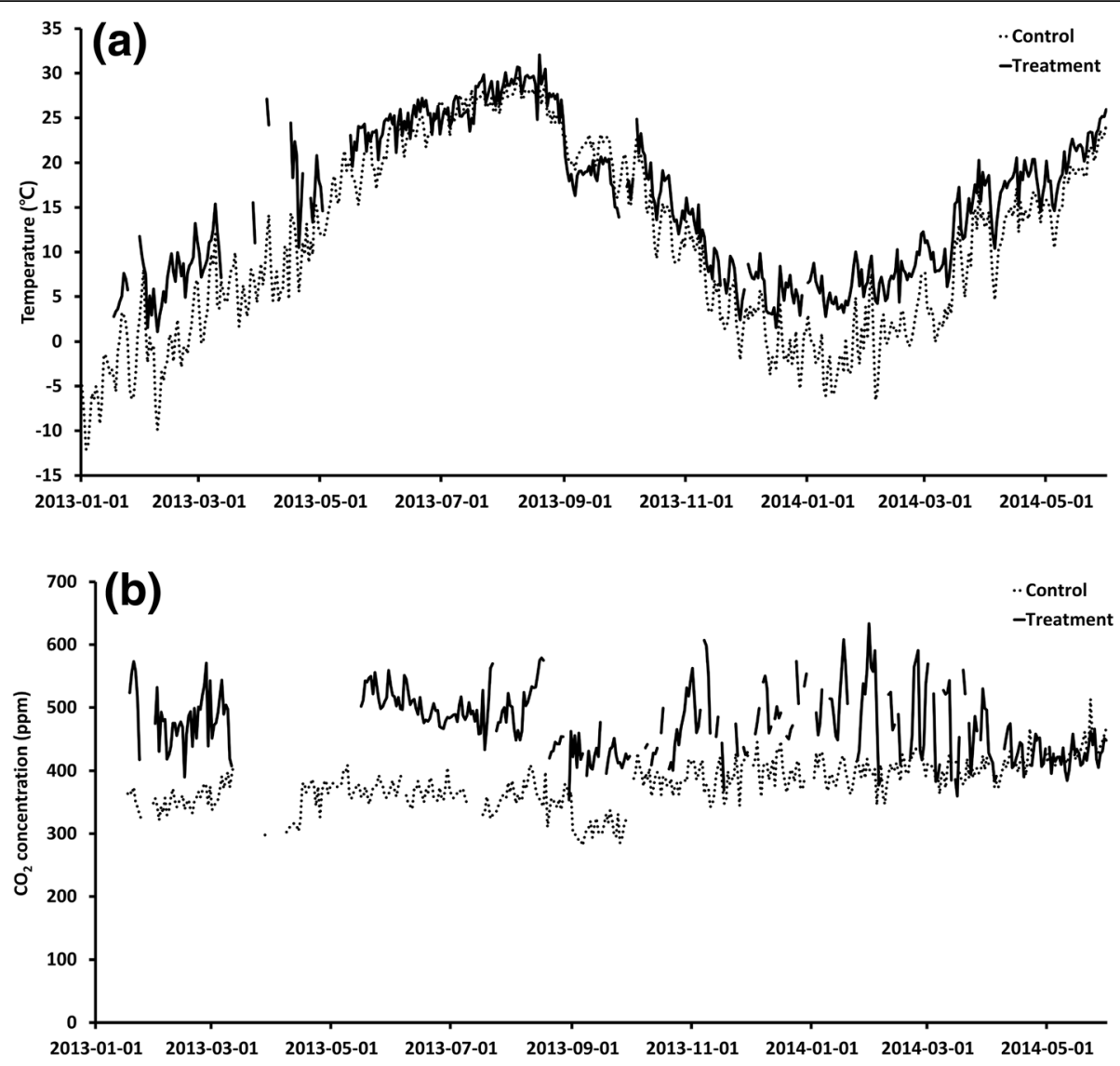

Fig. 1 The daily means of temperature (a) and $\mathrm{CO}_{2}$ concentration (b) in the control group (ambient conditions) and treatment group (climate change conditions) from January 2013 to May 2014

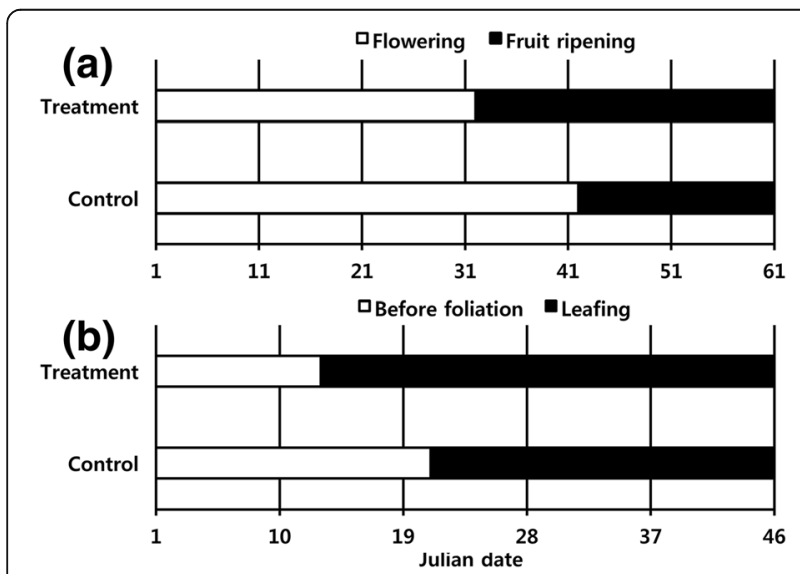

Fig. 2 The phenology of flowering, the fruit ripening from October to November 2013 (a; total 61 days), the duration before foliation in the soil after sowing, and the phenology of leafing of S. capitata from March to May 2014 (b; total 46 days) in the control group (ambient conditions) and treatment group (climate change conditions). The "1" day means the first day of flowering (a) and sowing seeds on the bed soil in the plate (b) using a chlorophyll content analyzer (CCM-200, ADC, Hoddesdon, UK). The chlorophyll fluorescence values, Fo and $\mathrm{Fm}$, were measured using a chlorophyll fluorescence analyzer (OS30p, ADC, Hoddesdon, UK) after adapting them to the dark for $20 \mathrm{~min}$ in October 2013. Fv/Fm, which is the photochemical efficiency of PSII, was calculated using the equation $(\mathrm{Fm}-\mathrm{Fo}) \div \mathrm{Fm}$ (Bjorkman and Demmig 1987).

\section{Statistical analysis}

Statistical analysis was performed using the Statistica 8 program (Statsoft Inc., Tulsa, US). Data were collected by observing the changes in growth and evaluating the physiological responses to climate change. The MannWhitney $U$ test was used to analyze variables. In addition, simple regression analysis was conducted on the transpiration rate, stomatal conductance, and photosynthetic rate to verify the correlational change among physiological items because climate change may occur in physiological adaptation or imbalance of plants. Significant probability for each statistical analysis was 0.05 (No and Jeong 2002). 


\section{Results and discussion Phenological changes}

Based on the observational results of phenological changes from the climate change treatment, the first day of flowering in 2013 showed no difference in both the control and treatment groups' condition on October 1 (Fig. 2a). Generally, the first day of the flowering of plants is expected to be advanced with increasing air temperature (IPCC 2014; Ministry of Environment 2018). But this result showed the starting day of the flowering has no difference between in the control group and in the treatment group. In the other studies, like this result, a change of flowering time appeared differently in some plant species (Springer and Ward 2007) which is thought to relate their ecological adaptation in an aspect of competing other plants or pollinators (Rathcke and Lacey 1985). The flowering mechanism is known to be controlled by photoperiod, temperature, age, and gibberellin in Arabidopsis thaliana (Song et al. 2013). Also, the $\mathrm{CO}_{2}$ concentration may have a role as hormone on the plant physiology (Moore et al. 1999). But mechanisms of that are known rarely even if flowering responses is affected that (Springer and Ward 2007).

The first day of fruit ripening in the treatment group was earlier than that in the control group, shortening the flowering time (Fig. 2a). This means that the first day of fruit ripening in the treatment group is advanced than in the control group. Therefore, the fruits of S. capitata may be ripened 10 days earlier under global warming condition than control. In the other studies of fruit ripening time, the fruit formation is advanced in Phytolocca insularis (Shin and You 2012), Phytolacca americana (Kim and You 2010b), and Cicuta virosa (Park et al. 2014b) when environment $\mathrm{CO}_{2}$ concentration and temperature increased. The shift of fruit ripening time is thought because of phenological plasticity on environmental change (Haggerty and Galloway 2011). Also, it is known that fruit ripening was regulated by ethylene (Mathooko 1996). In the case of sunflower (Helianthus annuus L.), the increase in $\mathrm{CO}_{2}$ controlled the production of ethylene (Dhawan et al. 1981). Therefore, it is thought that the increase of $\mathrm{CO}_{2}$ concentration may have influenced the ripening of fruit of S. capitata. But more reproductive data are needed for understanding relation between fruit ripening time and climate change.

The first day of leafing was also 8 days earlier than that in the control group (Fig. 2b). The climate change is thought to have a negative impact on reproduction by terminating flowering earlier. It also seemed that the leaf growth time would increase in the treatment group because of the earlier first day of leafing in 2014 and same first day of flowering in 2013.

\section{Growth and physiological changes}

The number of rosette leaves of S. capitata did not change, but the leaf area was wider in the treatment group than the control group (Fig. 3a, b). In similar studies, the leaf length and width of $P$. insularis, leaf width of $P$. americana (Kim and You 2010b), shoot height and number of leaves of Panax ginseng (Lee et al. 2012), and number of tillers of Cicuta virosa (Park et al. 2014b) increased when the environment's $\mathrm{CO}_{2}$ concentration and temperature increased.

The transpiration rate of S. capitata was higher in the treatment group than the control group (Fig. 4a). Similarly, the transpiration rate of $P$. insularis, $P$. Americana, and 1-year-old $P$. ginseng increased in an environment with a higher $\mathrm{CO}_{2}$ concentration and temperature (Kim and You 2010b; Lee et al. 2012). Commonly, it is known that transpiration rate decreases if $\mathrm{CO}_{2}$ concentration is elevated (Pessarakli 2001). In the high temperature, however, some crops undergo high water losses because of their low heat tolerance and undergo high water losses through transpiration (Pessarakli 2001). Thus, the result of transpiration rate in S. capitata suggests it may have a low heat tolerance.

The stomatal conductance of S. capitata was higher in the treatment group than the control group (Fig. 4b) while the water use efficiency did not differ between the control and treatment groups (Fig. 4c). It was reported the stomatal conductance of most crops decreases under elevated $\mathrm{CO}_{2}$ concentration with transpiration to improve their water use efficiency (Rogers and Dahlman 1993) and water use efficiency usually increases under high $\mathrm{CO}_{2}$ environment in short term (Morison 1993). Therefore, these conflicted results with this study seem to have an issue on the species-specific environmental tolerance because the physiological responses under enriched $\mathrm{CO}_{2}$ concentration can appear differently by species (Pessarakli 2001).

The photosynthetic rate did not differ between the control and treatment groups (Fig. 4d), and the chlorophyll content was lower in the treatment group than the control group (Fig. 4e). Similarly, the chlorophyll content of Oryza
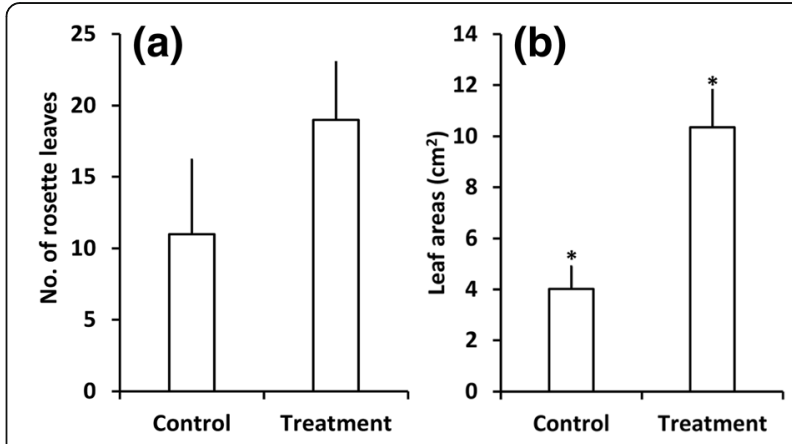

Fig. 3 The number of rosette leaves (a) and leaf areas (b) of $S$. capitata. The bars and error bars represent the average of each group and standard deviation, respectively. The asterisk (*) on the bars show a significant difference between the control group (ambient conditions) and treatment group (climate change conditions) 

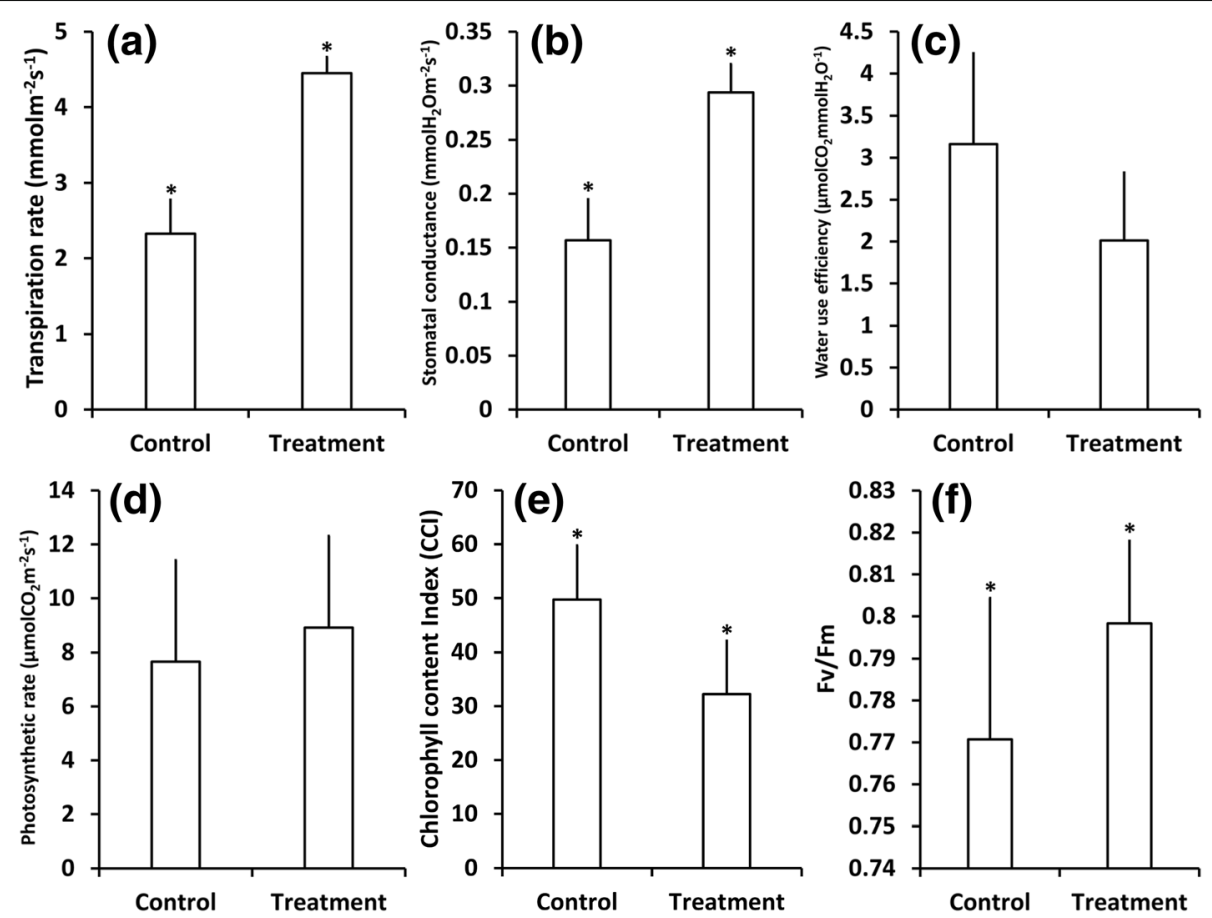

Fig. 4 The transpiration rate (a), stomatal conductance $(\mathbf{b})$, photosynthetic rate $(\mathbf{c})$, water use efficiency $(\mathbf{d})$, chlorophyll content (e), and Fv/Fm $(\mathbf{f})$ of S. capitata. The bars and error bars represent the average of each group and standard deviation, respectively. The asterisk $\left(^{*}\right)$ on the bars show a significant difference between the control group (ambient conditions) and treatment group (climate change conditions)

sativa L. cv. Junam decreased in an environment with a higher $\mathrm{CO}_{2}$ concentration and temperature (Kim and You 2010a). In general, plants are known to distribute resources in the direction of maximum relative growth rate (KastnerMaresch and Mooney 1994). Particularly, source-sink balance of carbohydrate may have control photosynthesis (Arp 1991). Therefore, the decrease in chlorophyll content in the treatment group is thought to be due to a plant trying to reduce excessively produced photosynthetic products because of the high $\mathrm{CO}_{2}$ environment and to redistribute the resources used to produce chlorophyll.

In this study, the amount of carbon fixed per second in a single leaf was roughly estimated by multiplying the photosynthesis rate by the average leaf area, giving $3.08 \times$ $10^{-3} \mu \mathrm{molm}^{-2} \mathrm{~s}^{-1}$ and $9.23 \times 10^{-3} \mu \mathrm{molm}^{-2} \mathrm{~s}^{-1}$ in the control and treatment groups, respectively. That is to say that three times as much carbon can be fixed, but an additional amount of water would be needed for transpiration in the treatment group than the control group (Fig. 4).

Also, considering these results of leaf area, transpiration rate, stomatal conductance, photosynthetic rate, and chlorophyll content, the relative increase in the amount of transpiration is thought to be due to the emission of excessive heat in the plant body, which is a result of the arise in temperature caused by the greenhouse effect resulting from a high $\mathrm{CO}_{2}$ concentration (Taiz and Zeiger 2002). Similarly, although the number of rosette leaves and stomata declined, the transpiration rate was higher and leaf temperature was lower when Arabidopsis thaliana grew for 4 weeks at $28^{\circ} \mathrm{C}$ compared with 3 weeks at $22^{\circ} \mathrm{C}$ and 1 week at $28^{\circ} \mathrm{C}$ (Crawford et al. 2012).

In this study, it is thought that the reason for the increased leaf area of S. capitata is to cool the leaf rapidly by increasing the leaf surface area rather than to produce photosynthetic products because of excessive temperature of leaves by elevated $\mathrm{CO}_{2}$ concentration (Taiz and Zeiger 2002). In a high-temperature environment, a leaf cooling system involving transpiration requires much water. In this study, the transpiration rate showed an approximate twofold difference (Fig. 4a).

In this study, if transpiration rate is multiplied by the mean leaf area, the consumed amount of water per leaf through transpiration was five times higher in the treatment group than the control group. Therefore, if the water supply is insufficient, water may become the limiting factor for plant survival as the environment undergoes intensified climate change in the future.

The chlorophyll fluorescence value, $\mathrm{Fv} / \mathrm{Fm}$, was higher in the treatment group than the control group (Fig. 4f). It is generally known that when the Fo value is increased or the $\mathrm{Fv} / \mathrm{Fm}$ value is decreased, photoinhibition due to environmental stress occurs (Bjorkman and Demmig 1987; Maxwell and Johnson 2000). Considering this, it may be expected that photosynthesis could be stabilized with less 
environmental stress in the treatment group than the control group. In case of $S$. capitata, considering increasing their transpiration rate and stomatal conductance in the treatment groups, it is thought that the reason of increasing $\mathrm{Fv} / \mathrm{Fm}$ value in the treatment groups may be related with a water stress. Generally, the occurred water stress causes the photoinhibition directly in photosynthetic machinery. In this study, the higher temperature of the treatment group than that of the control group can damage $S$. capitata by a water stress. But, due to supplied sufficient water, they may be able to act their stomatal control smoothly. Also, the area where these plants live is mainly in exposed surfaces of rocks. In direct sunlight, the temperature of the surrounding environment rises as the rock is heated. Considering this point, it is thought that the ideal environment of this plant may be high-temperature environment such as global warming treatment. But it is necessary to have a precise physiological research on the water stress of $S$. capitata for its exact diagnosis. Therefore, when climate change intensifies, areas in which the amount of water required for growth is sufficiently supplied will be stable habitats for growth.

\section{Simple regression analysis}

As a result of simple regression analysis on the transpiration rate, stomatal conductance, photosynthetic rate, and water use efficiency, it was found that the transpiration rate increased significantly with stomatal conductance in both the control and treatment groups and that the $r^{2}$ value was also very high (Fig. 5a). This result suggests that transpiration rate has the relation to stomatal control of S. capitata whether climate change will be accelerated or not.

The photosynthetic rate showed an increasing tendency with stomatal conductance and transpiration rate in the control group, but there was no such tendency in the treatment group (Fig. 5b, c). Water use efficiency also increased based on the transpiration rate and stomatal conductance in the control group. However, this trend was not observed in the treatment group (Fig. $5 \mathrm{~d}$, f). Generally, it is known that the opening and closing of stomata are controlled to maintain stable $\mathrm{CO}_{2}$ concentration for photosynthesis and to regulate water loss for water use efficiency in the intercellular space of a leaf (Hopkins and Huner 2009). It is thought that the stomata seemed to be controlled for photosynthesis and using water efficiently in the control. But, in the treatment, it seemed to be not controlled anymore for photosynthesis or protection of water loss. In the climate change environment, a large amount of $\mathrm{CO}_{2}$ can be easily introduced to intercellular space under rich $\mathrm{CO}_{2}$ in the air even if stomata are opened because of high partial pressure of air $\mathrm{CO}_{2}$ in
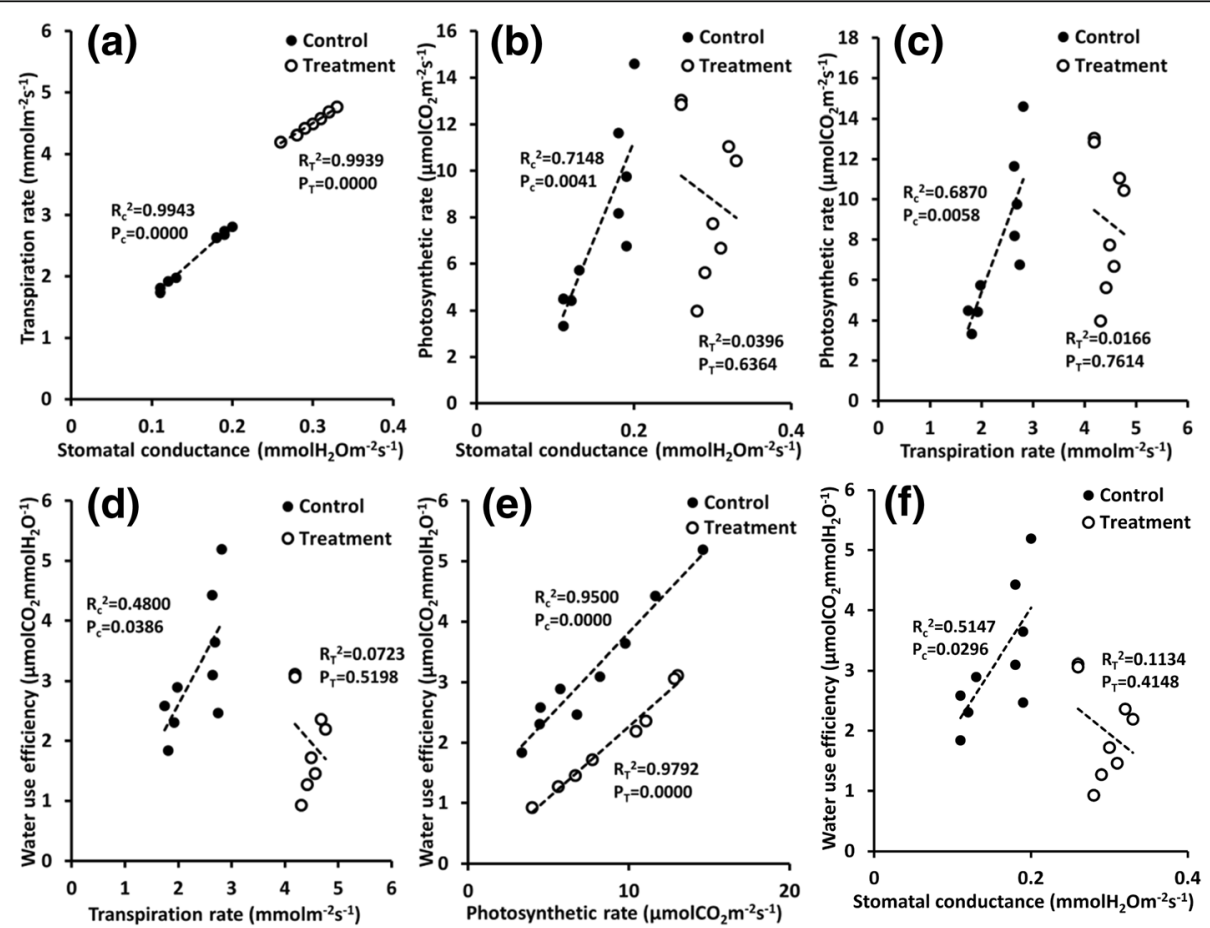

Fig. 5 The simple regression analysis results for transpiration rate $(\mathbf{a}, \mathbf{c}$, and $\mathbf{d})$, stomatal conductance $(\mathbf{a}, \mathbf{b}$, and $\mathbf{f})$, photosynthetic rate (b, $\mathbf{c}$, and $\mathbf{e}$ ), and water use efficiency ( $\mathbf{d}, \mathbf{e}$, and $\mathbf{f}$ ) in the control group (ambient conditions) and treatment group (climate change conditions). The $P_{C_{1}} R_{C}$ and $\mathrm{P}_{\mathrm{T}}$, and $\mathrm{R}_{\mathrm{T}}$ show a $p$ value and coefficient of determination in the control group (ambient conditions) and treatment group (climate change conditions), respectively $(p<0.05)$ 
terms of physics. Thus, it is considered that stomatal control is for transpiration activity to emit and remove accumulated heat in the body from high air temperature around a plant, not for increasing the photosynthetic rate.

Water use efficiency also increased with photosynthetic rate in both the control and treatment groups (Fig. 5e). It is known to close stomata in many plants for water loss under elevated $\mathrm{CO}_{2}$ level (Rogers and Dahlman 1993). But this result show, in the elevated $\mathrm{CO}_{2}$ condition, the photosynthesis may have a role of regulating water loss and efficient water use in S. capitata instead of the stomatal control.

\section{Conclusion}

These results show that the flowering period would be shortened under climate change environment because the first day of fruit ripening would be advanced while that of flowering would not change. The fruit productivity would be changed due to earlier ceasing of reproductive traits. But it is not clarified, and additional research on reproductive traits should be conducted. The first day of leafing of $S$. capitata would be advanced, and the vegetative growth period would be extended. In addition, the transpiration rate and stomatal conductance would increase while the chlorophyll content would decrease. Since $\mathrm{Fv} / \mathrm{Fm}$ increases in areas where sufficient water is supplied, it is considered that stable growth can be achieved in such circumstances due to less environmental stress.

In an environment with elevated $\mathrm{CO}_{2}$ concentration and temperature, the photosynthetic rate is no longer controlled by stomata due to the high $\mathrm{CO}_{2}$ concentration. This environment is expected to suppress excessive photosynthetic production by reducing chlorophyll content. It is also thought that the stomata are controlled for transpiration activity rather than for photosynthesis in order to release excessive heat in the plant body due to the increase in temperature. Therefore, if climate change continues, S. capitata could suffer damage to their growth development due to water stress in areas without a sufficient water supply, and their habitat would be limited to areas that can supply enough water. This study could be considered as a basic data for conservation researches and steps of S. capitata on the climate change. But additional studies are needed on the more detailed phenology, reproductive ecology, and responses of a variety of environmental stress.

\section{Acknowledgements}

This research was supported by the Basic Science Research Program through the National Research Foundation of Korea (NRF), funded by the Ministry of Education (NRF-2018R1D1A1B07050269).

\section{Authors' contributions}

All authors conducted a survey together during the study period. PJH wrote the manuscript, and $\mathrm{YYH}$ participated in the design of the study and examined the manuscript. All authors read and approved the final manuscript.

\section{Funding}

This research was supported by the Basic Science Research Program through the National Research Foundation of Korea (NRF), funded by the Ministry of Education (NRF-2018R1D1A1B07050269).

\section{Availability of data and materials}

Not applicable.

Ethics approval and consent to participate

Not applicable.

Consent for publication

Not applicable.

\section{Competing interests}

The authors declare that they have no competing interests.

\section{Author details}

${ }^{1}$ Department of Biological Science, Kongju National University, Gongju-si, Chungcheongnam-do 32588, Republic of Korea. ${ }^{2} \mathrm{~K}$-water Institute, KWATER, Yuseong-gu, Daejeon 34045, Republic of Korea. ${ }^{3}$ Division of Ecological Survey Research, National Institute of Ecology, Seocheon-gun, Chungcheongnam-do 33657, Republic of Korea. ${ }^{4}$ Division of Ecosystem Service and Research

Planning, National Institute of Ecology, Seocheon-gun, Chungcheongnam-do 33657, Republic of Korea.

Received: 25 March 2019 Accepted: 21 July 2019

Published online: 07 August 2019

\section{References}

Arp WJ. Effects of source-sink relations on photosynthetic acclimation to elevated $\mathrm{CO}_{2}$. Plant Cell Environ. 1991;14(8):869-75.

Bjorkman $\mathrm{O}$, Demmig B. Photon yield of $\mathrm{O}_{2}$ evolution and chlorophyll fluorescence characteristics at $77 \mathrm{~K}$ among vascular plants of diverse origins. Planta. 1987;170:489-504.

Choi $\mathrm{CH}$, Jung SG. Analysis of the MODIS-based vegetation phenology using the HANTS algorithm. J KAGIS. 2014;17(3):20-38. https://doi.org/10.11108/kagis. 2014.17.3.020.

Crawford AJ, McLachlan DH, Hetherington AM, Franklin KA. High temperature exposure increases plant cooling capacity. Curr Biol. 2012;22(10):R396-7.

Dhawan KR, Bassi PK, Spencer MS. Effects of carbon dioxide on ethylene production and action in intact sunflower plants. Plant Physiol. 1981;68(4):831-4.

Haggerty BP, Galloway LF. Response of individual components of reproductive phenology to growing season length in a monocarpic herb. J Ecol. 2011; 99(1):242-53.

Han YS, Kim HR, You YH. Effect of elevated $\mathrm{CO}_{2}$ concentration and temperature on the ecological responses of Aster altaicus var. uchiyamae, endangered hydrophyte. J Wetlands Res. 2012;14(2):169-80.

Hopkins WG, Huner NPA. Introduction to plant physiology. 4th ed. Hoboken: Wiley; 2009. p. 217.

IPCC. In: Pachauri RK, Meyer LA, editors. Climate change 2014: synthesis report. contribution of working groups I, II and III to the fifth assessment report of the intergovernmental panel on climate change [core writing team]. Geneva: IPCC; 2014. p. 2-83.

ISIIK K. Rare and endemic species: why are they prone to extinction? Turk J Bot. 2011;35(4):411-7. https://doi.org/10.3906/bot-1012-90.

Jeong Yl, Hong BR, Kim YC, Lee KS. Distribution, life history and growth characteristics of the Utricularia japonica Makino in the east coastal lagoon, Korea. KJEE. 2016:49(2):110-23.

Jung JY, Shin JK, Kim HG, Byun JG, Pi JH, Lee CH, et al. Study on conservation and habitat restoration based on ecological diagnosis for Cymbidium kanran Makino in Jeju island, Korea. KJEE. 2016:49(1):11-21.

Kang JS, Lee BY, Kwak M. The complete chloroplast genome sequences of Lychnis wilfordii and Silene capitata and comparative analyses with other Caryophyllaceae genomes. PLoS One. 2017;12(2):e0172924.

Kastner-Maresch AE, Mooney HA. Modelling optimal plant biomass partitioning. Ecol Model. 1994;75:309-20. 
Kim HR, You YH. The effects of the elevated $\mathrm{CO}_{2}$ concentration and increased temperature on growth, yield and physiological responses of rice (Oryza sativa L. cv. Junam). Adv Biores. 2010a;1 (2):46-50. https://doi.org/10.1504/ IJCAT.2010.034729.

Kim HR, You YH. Effects of elevated $\mathrm{CO}_{2}$ concentration and temperature on the response of seed germination, phenology and leaf morphology of Phytolacca insularis (endemic species) and Phytolacca americana (alien species). Kor J Env Eco. 2010b;24(1):62-8.

Lee EP, Han YS, Lee SI, Cho KT, Park JH, You YH. Effect of nutrient and moisture on the growth and reproduction of Epilobium hirsutum L., an endangered plant. J Ecol Environ. 2017:41(1):35.

Lee KM, Kim HR, Lim H, You YH. Effect of elevated $\mathrm{CO}_{2}$ concentration and temperature on the growth and ecophysiological responses of ginseng (Panax ginseng C. A. Meyer). Korean J Crop Sci. 2012;57(2):106-12.

Lee TB. (1975) Plant resource discovered (V). Kor J Plant Tax. 1975:6(1):17-19.

Mathooko FM. Regulation of ethylene biosynthesis in higher plants by carbon dioxide. Postharvest Biol Technol. 1996;7(1-2):1-26.

Maxwell K, Johnson GN. Chlorophyll fluorescence-a practical guide. J Exp Bot. 2000;51(345):659-68.

Ministry of Environment. 2018 White paper of environment. Sejong: Ministry of Environment; 2018. p. 45-47.

Moore BD, Cheng SH, Sims D, Seemann JR. The biochemical and molecular basis for photosynthetic acclimation to elevated atmospheric $\mathrm{CO}_{2}$. Plant Cell Environ. 1999;22(6):567-82.

Morison JIL. Response of plants to $\mathrm{CO}_{2}$ under water limited conditions. Vegetatio. 1993;104(1):193-209.

Nam GH, Kim JH, Kim YC, Kim JS, Lee BY. Floristic study of county Pyeong-chang and Yeong-wol including limestone regions (Prov. Gangwon-do) from Korea. Kor J Env Eco. 2012;26(1):11-38.

National Institute of Biological Resources (2011) https://species.nibr.go.kr. Accessed 21 Mar 2019

No HJ, Jeong HY. Well defined statistical analysis according to Statistica. Seoul: Hyungseul Publisher; 2002. p. 535-56.

Oh HK, Lee KE, Lee YH, Choung YS. Geographical distribution and ecology in microhabitats of the rare species, Pulsatilla tongkangensis Y.N. Lee et T.C. Lee. KJEE. 2014;47(Special):74-82.

Park JH, Cho KT, Kim SB, Jang RH, You YH. Effects of elevated- $-\mathrm{CO}_{2}$ concentration and -temperature on the phenological and reproductive responses of Baktae and Seomoktae, Glycine max (L.) Merrill. Kor J Environ Ecol. 2014a;28(6):634-41.

Park JH, Hong YS, Kim HR, Jeong JK, Jeong HM, You YH. Effects of elevated $\mathrm{CO}_{2}$ and temperate on the growth of endangered species, Cicuta virosa $\mathrm{L}$. in Korea. J Wetlands Res. 2014b;16(1):11-8.

Pessarakli M. Handbook of plant and crop physiology. 2nd ed. New York: Marcel Dekker Inc; 2001. p. 43.

Pi JH, Jung JY, Park JG, Yang HH, Kim EH, Suh GU, et al. Habitats environmental and population characteristics of Cypripedium japonicum Thunb., a rare species in Korea. KJEE. 2015;48(4):253-62.

Pi JH, Park JG, Jung JY, Park JS, Suh GU, Son SW. Habitats environmental and population characteristics of Iris koreana Nakai, a rare and endemic species in Korea. KJEE. 2016:49(2):102-9.

Rathcke B, Lacey EP. Phenological patterns of terrestrial plants. Annu Rev Ecol Syst. 1985;16:179-214.

Richardson AD, Keenan TF, Migliavacca M, Ryu Y, Sonnentag O, Toomey M. Climate change, phenology, and phenological control of vegetation feedbacks to the climate system. Agric For Meteorol. 2013;169:156-73.

Rogers HH, Dahlman RC. Crop responses to $\mathrm{CO}_{2}$ enrichment. Vegetatio. 1993; 104/105:117-31.

Shin $\mathrm{DH}$, You YH. Effects of elevated $\mathrm{CO}_{2}$ concentration and increased temperature on the change of the phenological and reproductive characteristics of Phytolocca insularis, a Korea endemic plant. J Wetlands Res. 2012:14:1): 1-9.

Song YH, Ito S, Imaizumi T. Flowering time regulation: photoperiod- and temperature-sensing in leaves. Trends Plant Sci. 2013;18(10):575-83.

Springer $\mathrm{CJ}$, Ward JK. Flowering time and elevated atmospheric $\mathrm{CO}_{2}$. New Phytol. 2007; $176: 243-55$

Taiz L, Zeiger E. (2002) Plant physiology. 3rd ed. Sunderland, US: Sinauer Associates; 2002. p. 34.

\section{Publisher's Note}

Springer Nature remains neutral with regard to jurisdictional claims in published maps and institutional affiliations.

Ready to submit your research? Choose BMC and benefit from:

- fast, convenient online submission

- thorough peer review by experienced researchers in your field

- rapid publication on acceptance

- support for research data, including large and complex data types

- gold Open Access which fosters wider collaboration and increased citations

- maximum visibility for your research: over $100 \mathrm{M}$ website views per year

At BMC, research is always in progress.

Learn more biomedcentral.com/submissions 